\title{
Determinan Premenstruasi Syndrome pada Siswi SMAN. 1 Unggul Darul Imarah Lampeunureut Aceh Besar
}

\section{Determinants of Premenstruation of Syndrome in Students of SMAN 1 Unggul Darul Imarah Lampeunureut Aceh Besar}

\author{
Agustina $^{*^{1}}$, Nurul Husna ${ }^{2}$ \\ ${ }^{1,2}$ Fakultas Kesehatan Masyarakat, Universitas Muhammadiyah Aceh, Banda Aceh, 23245 \\ *Korespondensi Penulis: agustina.260880@gmail.com
}

\begin{abstract}
Abstrak
Premenstruasi Sindrom (PMS) merupakan salah masalah yang umumterjadi pada wanita. 30$50 \%$ dari wanita mengalami gejala PMS, dan 5\% merasakan gejala cukup parah berdampak terhadap kesehatan fisik dan fungsi sosial. 10\% lainnya mengalami PMS yang sangat parah hingga menyebabkan ketidakhadiran disekolah. PMS ditandai dengan perubahan yang cepat dalam suasana hati misalnya, depresi, iritabilitas, kemarahan, agresi, mudah menangis, ketegangan, kecemasan, dan gejala fisik misalnya ketidaknyamanan payudara, nyeri pada perut, sakit kepala, kembung, edema, kelelahan, dan insomnia selama akhir siklus menstruasi. Memperbaiki gaya hidup dengan meningkatkan aktifitas fisik dan pola makan yang sehat dapat mengurangi terjadinya PMS. Penelitian ini bertujuan untuk mengetahui kejadian premenstruasi sindrom (PMS) ditinjau dari aktifitas fisik, pola tidur pada siswi di SMAN 1 Unggul Darul Imarah Aceh Besar.Penelitian ini bersifat deskriptifanalitikdengan menggunakan desain crossectional.Pengambilan sampel secara proporsional sampling sebanyak 72 responden. Hasil penelitiandiperoleh bahwa responden yang tidak mengalami gejala hingga gejala ringan terhadap kejadian premenstruasi sindrom sebanyak44 orang $(61,1 \%)$ dan responden yang mengalami gejala sedang hingga berat sebanyak 28 orang $(38,9 \%)$, kejadian premenstruasi sindrom tidak berhubungan denganaktifitas fisik dengan nilai $\mathrm{p}$ value $>0,05$. Sedangkan pola tidur berhubungan dengan kejadian premenstruasi sindrom dengan $\mathrm{p}$ value $<0,05$. Kesimpulan tingginya aktifitas fisik masih menjadi salah satu penyebab munculnya premenstruasi syndrome dan pola tidur yang tidak teratur juga akan memberikan dampak pada kejaian PM tersebut.
\end{abstract}

Kata Kunci : Kejadian Premenstruasi Sindrom, Pola tidur, Aktifitas Fisik

\begin{abstract}
Premenstrual Syndrome (PMS) is one of the most common problems in women. 30-50\% of women experience symptoms of PMS, and 5\% feel symptoms are severe enough to affect physical health and social function. The other $10 \%$ experienced very severe PMS to cause school absences. PMS is characterized by rapid changes in mood depression, irritability, anger, aggression, crying, tension, anxiety, and physical symptoms such as breast discomfort, abdominal pain, headache, bloating, edema, fatigue, and insomnia during late menstrual cycle. Improving lifestyle by increasing physical activity and a healthy diet can reduce the occurrence of PMS. This study aims to determine the occurrence of premenstrual syndrome $(P M S)$ in terms of physical activity, sleep patterns for girls at SMAN 1 Unggul Darul Imarah
\end{abstract}


Aceh Besar. This research is descriptive analytic using crossectional design. Sampling in proportional sampling as much as 72 respondents. The result of this study showed that respondents who did not experience symptoms until mild symptoms of premenstrual syndrome incident were 44 people (61.1\%) and respondents who experienced moderate to severe symptoms as many as 28 people (38.9\%), premenstrual syndrome not related to activity physical with $p$ value $>0,05$. While sleep patterns associated with premenstrual syndrome with $p$ value <0.05. The conclusion of high physical activity is still one of the causes of premenstrual syndrome and irregular sleep patterns will also have an impact on the incidence.

Keywords: Premenstrual Syndrome, Sleep Patterns, Physical Activity

\section{PENDAHULUAN}

Menstruasi merupakan proses katabolisme yang terjadi akibat adanya pengaruh dari hormon dihipofisis ke ovarium, seperti hormon estrogen dan progesteron. Umumnya menstruasi akan secara normal setiap bulan pada wanita usia subur (WUS) (Manuaba, 2009). Pada wanita biasanya 7-10 hari sebelum terjadi menstruasi akan mengalami beberapa gejala perubahan tertentu, dari segi fisik nyeri payudara, sakit kepala, jerawat, nyeri panggul, bahkan edema maupun emosional (perubahan mood), penurunan fungsi sosial, penurunan konsentrasi, bahkan depresi yang akan mereda ketika siklus menstruasi di mulai (NIH, 2014). Namun pada beberapa wanita juga dapat terjadi gejala yang terus berlanjut hingga 24-48 jam pertama siklus menstruasi dan akan mereda selama beberapa hari ke depan. Gejala-gejala tersebut biasa dikenal dengan premenstruasisindrom (PMS) (O’Brien dkk, 2007).

Dampak Premenstruasi Sindrom(PMS) bagi kesehatan reproduksi bisa mempengaruhifisik yaitu mudah terkena penyaki seperti Mioma, endrometriosis yang terjadi akibat adanya pengaruh dari ketidakseimbangan hormon estrogen dan progesteron (Sianipar, dkk, 2009).Bagi beberapa wanita gejala PMS dapat terjadi cukup parah, sehingga dapat menimbulkan dampak yang merugikan. Umumnya dampak dari PMS tersebut adalah gangguan aktivitas harian, seperti penurunan produktivitas kerja, sekolah, dan hubungan interpersonal penderita. Di samping itu PMS yang berat juga dapat berhubungan dengan kasus bunuh diri yang tinggi, tingkat kecelakaan, dan masalah kejiwaan akut (NIH, 2014).

Selanjutnya pada remaja putri (usia 14-19 tahun) di Iran, ditemukan bahwa dari 602 orang, $100 \%$ dilaporkan setidaknya pernah mengalami satu gejala premenstruasi sindrom yaitu nyeri perut (Delara dkk, 2012). Penelitian lainnya pada remaja putri di Turki, ditemukan sebanyak 61,4\% mengalami premenstruasi sindrom ringan dan 50,55 sedang hingga berat 
dengan gejala yang paling umum seperti stres 87,6\% dan kegelisahan 87,6\% (Deman dkk, 2004).

Di Indonesia dari 260 orang wanita usia subur, ditemukan sebanyak 95\% memiliki setidaknya satu gejala sindrom premenstruasi, dengan tingkat premenstruasi sindrom sedang hingga berat sebesar 3,9\% (Emilia, 2008).Pada dasarnya premenstruasi sindrom(PMS) pernah dialami hampir seluruh wanita di dunia. Dimana sebanyak $90 \%$ wanita mengalami setidaknya dua gejala dalam beberapa siklus menstruasi yaitu nyeri pada bagian perut dan payudara selama masa usia subur (WUS) dan 5-10\% wanita mengalami gejala tersebut yang bersifat sedang sampai berat (Wijayanti, 2009). Penelitian yang dilakukan oleh Rahmaniar dalam Nurmiaty dkk, 2011 di kota Purworejo pada siswi SMP, prevalensi premenstruasi sindromsebanyak 24,6\%. Penelitian lainnya juga dilakukan pada siswi SMA di kotaBogor, ditemukan bahwa seluruh responden mengalamipremenstruasisindrom, dengan jenis keluhan ringansebanyak 32,2\% dan keluhan sedang sampai berat sebanyak 67,8\% (Aldira 2014).

Namun sampai saat ini penyebab dari premenstruasisindrom belum diketahui secara pasti. Walaupun dari beberapa literatur yang ada, dikatakan bahwa faktor penyebab utamanya adalahfaktor hormonal akibat adanya ketidakseimbangan kerja dari hormon estrogen dan progesteron serta adanya perubahan kadar serotonin (Saryono dan Sejati, 2009).Selainfaktor hormonal, ada beberapa faktor lain yang berhubungan dengan timbul dan parahnya gejala premenstruasisindrom, faktor tersebut adalah gaya hidup.Untuk faktor gaya hidup, terbagi menjadi beberapa faktor lainnya seperti status gizi berdasarkan IMT dan aktifitas fisik. Faktor status gizi memiliki peranan yang cukup penting pada tingkat keparahan kejadian premenstruasisindrom. Berdasarkan sebuah penelitian, ditemukan bahwa obesitas memiliki keterkaitan dengan kejadiaan PMS. Sependapat dengan penelitian tersebut, penelitian lainnya juga mendapatkan bahwa setiap kenaikan $1 \mathrm{~kg} / \mathrm{m}^{2}$ pada IMT dikaitkan dengan peningkatan yang signifikan terhadap resiko premenstruasisindrom sebesar 3\% (Masho dkk, 2005).

Sedangkan faktor aktifitas fisik merupakan faktor yang dapat mengurangi rasa sakit akibat premenstruasisindrom, dimana dengan rendahnya aktifitas fisik juga dapat meningkatkan keparaha gejala, seperti rasa tegang, emosi, dan depresi. Berdasarkan penelitian yang telah dilakukan, ditemukan bahwa aktivitas fisik secara signifikan dapat menurunkan resiko gejala premenstruasisindrom, seperti perubahan nafsu makan, hipersensitivitas emosi, dan sakit kepala (Sianipar, dkk, 2009, Kroll, 2010). 
Data Riset Kesehatan Dasar 2014, angka kesakitan karena Premenstruasi Sindrom (PMS) yang di sebabkan perubahan nafsu makan 15\%, payudara terasa bengkak $42 \%$ sakit kepala $10 \%$ dan yang disebabkan oleh faktor hormonal yaitu akibat adanya ketidakseimbangan kerja dari hormon estrogen dan progesteron sebesar 74,45\%. Data yang di peroleh dari Dinas Kesehatan Aceh Besar tahun 2015 wanita usia subur (WUS) terdapat 95,1\% yang mengalami premenstruasi sindrom (PMS) ringan hingga berat. Sedangkan di tahun 2016 wanita usia subur (WUS)yang mengalami premenstruasi sindrom (PMS) sebesar $71 \%$.

Berdasarkan data dari PuskesmasKecamatan Darul Imarah tahun 2015 wanita usia subur diketahuiyang mengalami premenstruasi sindrom (PMS) sebesar 47\% pada remaja. Sedangkan di tahun 2016 diketahui bahwa remaja di wilayah Puskesmas Darul Imarah mengalami premenstruasi sindrom (PMS)sebesar 11,0\%.Dari 11 siswi yang telah diwawancarai, mengatakan mereka sering mengeluh akibat PMS seperti Sakit punggung, mual, muntah, perut kembung, payudara terasa bengkak dan nyeri perut sehingga mengakibatkan siswi kehilangan konsentrasi saat belajar.Maka peneliti tertarik untuk mengetahui lebih mendalam tentang hubungan kejadian premenstruasi sindromdengan faktorfaktornya pada siswi SMAN 1 Unggul Darul Imarah LampeunerutAceh Besar.

\section{METODE PENELITIAN}

Penelitian ini bersifat deskriptifanalitik dengan menggunakan desain crossectional. Penelitian ini dilakukan di SMA 1 unggul Darul Imarah Lampeuneurut Aceh Besar Tahun 2017. Jumlah Populasi 245 siswi dengan pengambilan sampel menggunakan metode proporsional random sampling sebanyak 72 responden yang diundi secara acak (random).

\section{HASIL DAN PEMBAHASAN}

1. Kejadian Premenstruasi Sindrom (PMS)

Tabel 1. Kejadian Premenstruasi Sindrom pada Siswa di SMAN Unggul Darul Imarah Lampeuneurut Aceh Besar

\begin{tabular}{clcc}
\hline No & Kejadian Premenstruasi Sindrom & Frekuensi & \% \\
& (PMS) & & \\
\hline 1 & Gejala Sedang Hingga Berat & 28 & 38,9 \\
2 & Tidak ada Gejala Hingga Gejala Ringan & 44 & 61,1 \\
\hline & Total & 72 & 100 \\
\hline
\end{tabular}

Sumber : Data Primer (Diolah Juni, 2017) 
Hasil penelitian dari 72 orang responden, yang mengalami gejala sedang hingga berat kejadian premenstruasi sindrom (PMS) sebanyak28 orang $(38,9 \%)$ dan responden yang tidak mengalami gejala hingga gejala ringan sebanyak 44 orang $(61,1 \%)$.

2. Kejadian Premenstruasi Sindrom (PMS) di Tinjau dari Aktifitas Fisik

Tabel 2. Kejadian Premenstruasi Sindrom Ditinjau dari Aktifitas Fisik pada Siswa di SMAN Unggul Darul Imarah Lampeuneurut Aceh Besar

\begin{tabular}{|c|c|c|c|c|c|c|c|c|}
\hline \multirow[t]{3}{*}{ No } & \multirow[t]{3}{*}{$\begin{array}{l}\text { Aktivitas } \\
\text { Fisik }\end{array}$} & \multicolumn{4}{|c|}{$\begin{array}{c}\text { Kejadian Premenstruasi Sindrom } \\
\text { (PMS) }\end{array}$} & \multirow{2}{*}{\multicolumn{2}{|c|}{ Total }} & \multirow[t]{2}{*}{ P value } \\
\hline & & \multicolumn{2}{|c|}{$\begin{array}{c}\text { Gejala Sedang } \\
\text { Hingga Berat }\end{array}$} & \multicolumn{2}{|c|}{$\begin{array}{c}\text { Tidak ada } \\
\text { Gejala Hingga } \\
\text { Gejala Ringan }\end{array}$} & & & \\
\hline & & $\mathrm{n}$ & $\%$ & $\mathrm{n}$ & $\%$ & $\mathrm{n}$ & $\%$ & \\
\hline 1 & Ringan & 12 & 16,7 & 15 & 20,8 & 27 & 100 & \\
\hline 2 & Sedang & 11 & 15,3 & 11 & 15,3 & 22 & 100 & 0,114 \\
\hline 3 & Berat & 5 & 6,9 & 18 & 25,0 & 23 & 100 & \\
\hline Total & & 28 & 38,9 & 44 & 61,1 & 72 & 100 & \\
\hline
\end{tabular}

Sumber : Data Primer (Diolah Juni, 2017)

Berdasarkan tabel di atas diketahui bahwa proporsi responden yang mengalami gejala sedang hingga berat saat melakukan aktivitas fisik ringan lebih banyak $(15,3 \%)$ dibandingkan saat melakukan aktivitas fisik sedang $(15,3 \%)$ dan aktivitas fisik berat $(6,9 \%)$. Sedangkan pada responden yang tidak mengalami gejala hingga gejala ringan saat melakukan aktivitas fisik berat lebih banyak (25,0\%) dibandingkan saat melakukan aktivitas fisik ringan $(20,8 \%)$ dan aktivitas fisik sedang (15,3\%).Hasil uji statistik juga menunjukkan bahwa tidak ada hubungan yang signifikan (bermakna) antara Kejadian Premenstruasi Sindrom (PMS) dengan aktivitas fisik yaitu dengan nilai $\mathrm{P}$ value $=0,114$. Dengan demikian responden yang melakukan aktivitas fisik berat tidaksemuanya memiliki gejala premenstruasi sindrom (PMS). 
3. Kejadian Premenstruasi Sindrom (PMS) diTinjau dari Pola Tidur

Tabel 3. Kejadian Premenstruasi Sindrom Ditinjau dari Pola Tidur pada Siswa di SMAN Unggul Darul Imarah Lampeuneurut Aceh Besar

\begin{tabular}{|c|c|c|c|c|c|c|c|c|}
\hline \multirow[t]{3}{*}{ No } & \multirow[t]{3}{*}{ Pola Tidur } & \multicolumn{4}{|c|}{$\begin{array}{l}\text { Kejadian Premenstruasi } \\
\text { Sindrom (PMS) }\end{array}$} & \multirow{2}{*}{\multicolumn{2}{|c|}{ Total }} & \multirow[t]{2}{*}{$P$ value } \\
\hline & & \multicolumn{2}{|c|}{$\begin{array}{l}\text { Gejala Sedang } \\
\text { Hingga Berat }\end{array}$} & \multicolumn{2}{|c|}{$\begin{array}{c}\text { Tidak ada } \\
\text { Gejala Hingga } \\
\text { Gejala Ringan }\end{array}$} & & & \\
\hline & & $\mathrm{n}$ & $\%$ & $\mathrm{n}$ & $\%$ & $\mathrm{n}$ & $\%$ & \\
\hline 1 & Buruk & 20 & 27,8 & 17 & 23,6 & 37 & 100 & 0,013 \\
\hline 2 & Baik & 8 & 11,1 & 27 & 37,5 & 35 & 100 & \\
\hline & Total & 28 & 38,9 & 44 & 61,1 & 72 & 100 & \\
\hline
\end{tabular}

Sumber : Data Primer (Diolah Juni, 2017)

Dari tabel di atas diketahui bahwa proporsi responden yang mengalami gejala sedang hingga berat dengan pola tidur buruk lebih banyak $(27,8 \%)$ dibandingkan responden dengan pola tidur baik $(11,1 \%)$. Sedangkan pada responden tidak ada mengalami gejala hingga gejala ringan dengan pola tidur baik yang lebih banyak (37,5\%) dibandingkan responden dengan pola tidur buruk $(23,6 \%)$. Hasil uji statistik juga menunjukkan bahwa ada hubungan yang signifikan (bermakna) antara Kejadian Premenstruasi Sindrom (PMS) dengan pola tidur yaitu dengan nilai $\mathrm{P}$ value $=0,013$. Dengan demikian responden dengan pola tidur buruk tidak semuanya memiliki gejala premenstruasi sindrom (PMS).

\section{Pembahasan}

1. Kejadian Premenstruasi Sindrom (PMS) di Tinjau dari Aktifitas Fisik

Dari hasil penelitian ini diketahui bahwa tidak ada hubungan yang signifikan (bermakna) antara Kejadian Premenstruasi Sindrom (PMS) dengan aktivitas fisik yaitu dengan nilai $\mathrm{P}$ value $=0,114$ yang menunjukkan bahwa Ho diterima atau hipotesis penelitian ditolak yaitu tidak ada hubungan antara aktivitas fisik dengan kejadian PMS. Responden yang melakukan aktivitas fisik berat tidakberhubungan dengan gejala sedang hingga berat pada kejadian Premenstruasi Sindrom (PMS). Hasil penelitian ini sejalan dengan penelitian yang dilakukan oleh Pujihastuti (2012) dan Aldira (2014) yang juga menemukan bahwa tidak ada hubungan antara aktivitas fisik dengan PMS.

Hasil penelitian lapangan menunjukkan bahwa responden yang melakukan aktivitas fisik ringan lebih banyak (37,5\%) dibandingkan responden yang melakukan aktivitas fisik sedang dan berat. Berdasarkan tabel distribusi frekuensi aktivitas fisik siswi SMAN 1 
Unggul Darul Imarah Lampeuneurut Aceh Besar diketahui bahwa responden dengan aktivitas fisik ringan sebanyak 20,8\% yang tidak mengalami gejala ringan, sedangkan responden dengan aktivitas fisik sedang sebanyak 15,3\% dan responden dengan aktivitas fisik berat sebanyak 25,0\% yang tidak mengalami gejala ringan. Hal ini diketahui bahwa responden dengan aktivitas fisik ringan cenderung lebih banyak yang tidak mengalami gejala hingga gejala ringan dibandingkan dengan aktivitas fisik sedang dan berat.Hasil dari analisa data tidak ada hubungan antara aktivitas fisik dengan kejadian PMS. Jadi, aktivitas fisik bukan satu-satunya faktor yang mempengaruhi PMS. Sepertinya halnya faktor riwayat keluarga yang memainkan peranan penting pula terhadap perubahan serotonin atau pun faktor psikologis yang berhubungan dengan hormon progesteron. Sehingga apabila faktor yang lain terpenuhi, risiko PMS tetap dapat diturunkan (Michel dan Bonnet, 2014).

Namun peneliti berasumsi bahwa berdasarkan hasil recall aktivitas fisik, tingginya prevalensi aktifitas fisik ringan pada penelitian ini disebabbkan karena sebagian besar aktifitas responden pada hari senin sampai jumat adalah belajar (sekolah dan tempat les), mereka hanya melakukan duduk sambil menulis atau membaca. Sedangkan pada hari libur, sebagian besar responden menghabiskan waktu dengan beristirahat, seperti tidur dan bermain gadget. Disamping itu sebagian besarresponden pergi dan pulang sekolah menggunakan kendaraan pribadi, hanya sebagian kecil yang menggunakan angkutan umum dan perlu sedikit berjalan untuk sampai ke tempat tujuan. Hal ini diperkuat dengan penelitian Aldira (2014), yang juga menemukan bahwa alasan tingginya aktivitas fisik ringan yang terjadi pada remaja putri dikarenakan hal tersebut.

2. Kejadian Premenstruasi Sindrom (PMS) ditinjau dari Pola Tidur

Dari hasil penelitian ini diketahui bahwa bahwa ada hubungan yang signifikan (bermakna) antara Kejadian Premenstruasi Sindrom (PMS) dengan pola tidur yaitu dengan nilai $\mathrm{P}$ value $=0,013$ yang menunjukan bahwa Ho ditolak atau hipotesis penelitian diterima yaitu ada hubungan antara pola tidur dengan kejadian PMS. Artinya siswi yang memiliki pola tidur buruk berpeluang untuk mengalami PMS gejala sedang hingga berat.Hasil penelitian lapangan menunjukkan bahwa responden yang memiliki pola tidur buruk lebih banyak $(51,4 \%)$ dibandingkan reponden yang memiliki pola tidur baik $(48,6 \%)$. Dari $51,4 \%$ responden yang memiliki pola tidur buruk terdapat $27,8 \%$ responden 
yang kejadian PMS sedang hingga berat. Sedangkan dari 48,6\% responden yang memiliki pola tidur baik terdapat $11,1 \%$ responden yang mengalami gejala PMS sedang hingga berat. Hal ini menunjukkan bahwa cenderung responden yang memiliki pola tidur buruk lebih banyak yang mengalami PMS sedang hingga berat, dibandingkan dengan responden yang memiliki pola tidur baik.

Penilaian baik buruknya tidur responden dalam penelitian ini dilihat dari pola tidur. Pola tidur yang di maksud adalah kebiasaan tidur responden dalam satu bulan terakhir yang diukur melalui tujuh komponen utama, yaitu kualitas tidur, letensi tidur, durasi tidur, efisiensi tidur, gangguan tidur, penggunaan obat tidur, dan gangguan aktivitas di siang hari.Buruknya latensi tidur dan kualitas tidur pada siswi di SMAN 1 Darul Imarah dapat disebabkan oleh penggunaan media elektronik (gadget), seperti handphone maupun tablet. Sebab telah kita ketahui bahwa di zaman sekarang ini penggunaan gadget sangat umum di masyarakat, khususnya para remaja yang cenderung mengikuti tren.

Hasil penelitian ini sejalan dengan penelitian yang serupa dengan menggunakan kuesioner PSQI, menemukan bahwa PMS memiliki hubungan dengan buruknya kualitas tidur. Dimana pola tidur yang baik (tidur tanpa gangguan) ternyata dapat meringankan gejala PMS. Hal ini dikarenakan baik dan buruknya pola tidur akan mempengaruhi sekresi berbagai hormon yang ada di dalam tubuh (Shechter dan Boivin, 2010). Di samping itu menurut Baker, dkk (2007), meskipun pola tidur yang buruk merupakan salah satu gejala dari PMS yang parah, namun berdasarkan hasil penelitiannya diketahui bahwa pola tidur yang buruk akan meningkatkan keparahan dari gejala PMS yang dirasakan. Di samping itu berdasarkan hasil uji chi-square diketahui pula bahwa komponen dari pola tidur yang berhubungan dengan PMS adalah latensi tidur, kualitas tidur, dan gangguan aktivitas di siang hari.Hasil tersebut menunjukan bahwa, siswi yang mengalami latensi tidur> 60 menit memiliki berpeluang mengalami PMS gejala sedang hingga berat, siswi yang memiliki kualitas tidur buruk berpeluang untuk mengalami PMS gejala sedang hingga berat, dan siswi yang mengalami PMS gejala sedang hingga berat berpeluang mengalami gangguan aktivitas di siang hari $\geq 3$ kali dalam seminggu.

Menurut peneliti berasumsi bahwa terdapat hubungan antara kejadian premenstruasi sindrom karena berdasarkan hasil pengumpulan data diketahui bahwa pola tidur siswi SMAN 1 Darul Imarah sebagian besar kurang memenuhi syarat. Hal ini dibuktikan dari hasil pengumpulan data, diketahui banyak siswi yang mengalami gangguan aktifitas pada 
siang hari, seperti mengantuk, yang mungkin disebabkan adanya letensi tidur dan kualitas tidur yang buruk. Salah satu yang dapat dilakukan adalah dengan meningkatkan upaya untuk memperbaiki latensi dan kualitas tidur, yang mungkin dapat dilakukan dengan cara mengurangi penggunaan gadget. Hal ini sejalan dengan penelitian Shechter dan Boivin (2010) yang menemukan bahwa PMS memiliki hubungan dengan pola tidur.

\section{KESIMPULAN}

Tidak ada hubungan yang signifikan (bermakna) antara Kejadian Premenstruasi Sindrom (PMS) dengan aktivitas fisik yaitu dengan nilai $\mathrm{P}$ value $=0,114<0,05$. Artinya tingginya prevalensi aktifitas fisik ringan pada penelitian ini disebabbkan karena sebagian besar aktifitas responden pada hari senin sampai jumat adalah belajar (sekolah dan tempat les), mereka hanya melakukan duduk sambil menulis atau membaca. Sedangkan untuk Pola Tidur ada hubungan yang signifikan (bermakna) antara Kejadian Premenstruasi Sindrom (PMS) dengan pola tidur yaitu dengan nilai $\mathrm{P}$ value $=0,013>0,05$. Artinya baik dan buruknya pola tidur seseorang sangat mempengaruhi beratnya gejala PMS.

\section{SARAN}

1. Institusi sekolah melalui UKS

Diharapkan dapat melakukan promosi kesehatan berupa pembuatan pedoman atau media kesehatan yang mudah dipahami dan menarik, yang berkaitan dengan PMS, pola tidur yang baik dan konsumsi zat kalsium sesuai kebutuhan remaja.

2. Instansi kesehatan

Diharapkan dapat memberikan informasi kepada petugas kesehatan lainnya tentang pentingnya kesehatan reproduksi khususnya pada remaja, dan dapat mengadakan kegiatan promosi kesehatan berupa penyuluhan atau pembuatan media kesehatan.

\section{DAFTAR PUSTAKA}

ACOG.(2006). Menstruasi in Girls and Adolescent: Using the Menstrual Cycle as a Vital Sing. Jakarta: Buku Kedokteran

Aldira, C. F. (2014). Hubungan Aktifitas fisik dan Stres dengan Sindrom Pramenstruasi pada remaja putri di SMA Bina Insani Bogor. Skripsi, Institut Pertanian Bogor.

Almatsier, S. (2010). Prinsip Dasar Ilmu Gizi, Jakarta, PT Gramedia Pustaka Utama. 
Amjad, A., Kumar, R. dan Mazher, S. B. (2014).Socio-demographic Factors and premenstrual syndrom among Women attending a Teaching Hospital in Islamabad, Pakistan. J Pioneer Med Sci, 4, 4.

Bangga, A dan Kulkami, S. (2000). Age at Menarche and Secular Trend in Maharashtrian (Indian) Girls. Acta Biologica Szegediensis, 44, 5.

Baker,F.C.,Kahan,T.L., Trinder, J. Dan Colrain, I. M. (2007). Sleep Quality and the Sleep Electroencephalogram in Women With Severi Premenstrual Syndrome, Sleep,30,1283-1291.

Benson, R. C dan pernoll, M. L. (1994).Buku Saku Obsetri dan Ginekologi, Jakarta, Penerbit Buku Kedokteran EGC.

Brahmbhatt, S., Sattigeri, B. M., Shah, H., Kumar, A. Dan Parikh, D. (2013).A prospective Survey Study on Premenstrual Syindrom in in Young and Middle Aged Women With an Ermphasis on Its Managemen. Int J Med Sci, 1,69-72.

Cheng, S. H., Shih, C. C., Yang, Y. K, Chen, K. T., Chang Y.H. dan Yang, y. C. 2013. Faktors Associated with Premernstrual Syndrme A Survey of New Female Universitay Studnts. Kaohsiung Journal of Medical Sciences, 29,6

Depkes.(2014). Hal-hal yang Mempengaruhi Kebutuhan Gizi: Kategori Tingkat Aktivitas.

Dinkes.(2014). Hal-hal yang Mempengaruhi Kebutuhan Gizi : Jakarta, Pusat data dan Informasi Depkes RI.

,. Pelayanan Kesehatan tentang kejadian premenstruasi sindromMenurut Kecamatan Dan Puskesmas Tahun 2014, Banda Aceh, 2015

Delara, M.,Ghofranipour, F., Azadfallah, P., Tavafian, S. S., Kazemnejad, A. Dan Montazeri, A. 2012. Health Related Quality of Life Among Adolescents With Premenstrual Disorders: a Cross Sectional Study. Health and Quality of life Oucomes, 10.

Emilia, O. (2008). Premenstrual Syndrome and Premenstrual Dysphoric Disorder (PMDD) in Indonesia Women. Journal of the Medical Sciences, 40.

Kemenkes (2014).Riset Kesehatan Dasar 2014. Jakarta: Badan penelitian dan pengembangan Kesehatan Kemenkes RI.

Kemenkes (2011). Standar Antropometri Penelitian Status Gizi Anak, Jakarta, Direktorat Jenderal Bina Gizi dan Kesehatan Ibu dan Anak Kemenkes RI.

Kemenkes (2014).Pedoman Gizi seimbang, Jakarta, Direktorat Jenderal Bina Gizi dan Kesehatan Ibu Anak Kementerian Kesehatan RI.

Lee, M, Kim, J., Lee, J. Dan Kim, D. (2002). The Standardization of the Shortened Premenstrual Assessment Form and Applicability on the Internet. J Korean Neuropsychiatr Assoc, 41,8.

Manuaba, 2009.Ilmu Kesehatan Masyarakat, Jakarta, Rineka Cipta.

Marjoribanks, J., Brown, J., O’Brien, P. M. Dan Wyatt, K. (2013). Selective Serotonin Reuptake Inhibitors for Premenstrual Syndrome, Yogyakarta, Nuha Medika. 
Masho, S., Adera, T. Dan South Paul, J. (2005).Obesity as a Risk Faktor for Premenstruasi syndrome.J Psychosom Obstet Gynaecol., 26,6.

Mayyane.(2011). Hubungan antara Tingkat Stres dengan Kejadian Sindrom premenstruasi pada siswi SMA Negeri 1 padang Panjang Tahun 2011. Sripsi, Universitas Andalas.

Michel, C L. Dan Bonnet, X. (2014). Effect of a brief stress on progesterone plasma levels in pregnant and non-pregnant guinea pigs. Animal Biology, 64, 19-29.

Moghadam, .D., Sayehmiri, K., Delpisheh, A. Dan Kaikhavandi, S. (2014). Epidemiology of Premenstrual Syindrom (PMS)-A Systematic Review and Meta-Analysis Study. Journal of Clinical and Diagnostic Research : JCDR, 8,106-109.

Munthe, N. B. G. (2013). Hubungan Status Gizi dengan Kejadian Premenstrual Syindrome pada Remaja Putri di SMP Negiri 3 Berastagi. Skripsi, Universitas Sumatra Utara.

Notoatmodjo, S. (2007).Ilmu Kesehatan Masyarakat, Jakarta, Rineka Cipta.

Nurmiaty, Wilopo, S. A dan Sudargo, T. (2011).Perilaku Makan dengan Kejadian Sindrom Premenstruasi pada Remaja. Berita Kedokteran Masyarakat, 27,7

NIH.2014. Premenstruasi Syindrom [Online]. United states: National Institute of Health.

Nurmiaty, Wilopo, S.A. dan Sudargo, T. (2011). Perilaku Makan dengan kejadian premenstruasi sindrom pada Remaja. Berita Kedokteran Masyarakat, 27,7.

O’Brien, P.S., Rapkin, A. J. Dan Schmidt, P.J. (2007). The Premenstrual Syndromes: PMS and PMDD, London, Informa Healthcare.

Praschack-Rieder, (2002). Role of Family History and 5-HTTLPR Polymorphism in female Seasonal Affective Disorder Patiend With and Without Premenstrual Dysphoric Disorder. Eur Neuropsychopharmacol, 12,129-34.

Saryono dan Sejati, W. 2009.PremenstruasiSindrom, Yogyakarta, Nuha Medika.

Shechter, A. Dan Boivin, D. B. (2010). Sleep, Hormones, and Circadian Rhythms throughout the Menstrual Cycle in Healthy Women with Premenstrual Dysphoric Disorder. International Journal of Endocrinology, 2010, 17.

Sianipar, O., Bunawan, N.C., Almazini, P., Calista, N., Wulandari, P., Rovenska, N., Djuanda, R.E., Irene, Seno, A. Dan Suarthana, E. 2009. Prevalensi Gangguan Menstruasi dan Faktor-faktor yang Berhubungan pada siswi SMU di Kecamatan Pulo Gadung Jakarta Timur. Artikel Penelitian Maj Kedokt Indon,59

Silvia, C. M. L. D., Gigante, D. P. Dan Minten, G. C. 2008. Premenstrual Symptome According to Age at Menarche in a 1982 Birth cohort in Southern Brazil.Cad. Saude Publica, Rio de Janeiro,24,10.

Siyamti, S. dan Pertiwi, H. W. (2011).Hubungan antara Tingkat Kecemasan dengan Premenstruasi Sindrom pada Mahasiswi Tingkat II Akademi Kebidanan Estu Utomo Boyolali. Jurnal Kebidanan, 3.

Tolossa, F.W. dan Bekele, M. L (2014).Prevalence, Impacts and Medical Managements of Premenstruasi Syindrome among Female Student: Cross-Sectional Studyin college of 
Health Sciences, Mekelle University, Mekelle, Norhern Ethiopia. BMC Women's Health, 14

UMM. (2013). Premenstrual syndrome.Thesis, Universitas Gajah Mada.

Visser, A K D., van Waarde, A., Willemsen, A. T. M., Bosker, F. J ., Luiten, P. G.M., den Boer, J. A., Kema, I.P dan Dierckx, R. 2011. Measuring Serotonin Synthesis: from Conventional Methods to PET Tracers and Their (Pre) Clinical Implications. Eur J Nucl Med Mol Imaging, 38, 576-91

WHO. (2011). Kesehatan Reproduksi.[Online].Wwitzerland: World Health Organization Available:http://www.who.int/dietphycalactivity/pa/en/16 juni 2011].

Wijaya, A. (2006). Biologi IX, Jakarta, Penerbit Grasindo.

Wijayanti, (2009).Reproduksi Wanita. Yogyakarta: Diglossia Printika.

Young, S.N. (2007). How to Increase Serotonim in The Human Brain without Drugs.

J Psychiatry Neorpsci, 32,5.

Zaka, M. Dan Mahmood, K. T. (2012). Premenstruasi Syndrome-a Review J. Pharm. Sci. \& Res., 4,7 